\title{
Ultrastructural demonstration of the model of Litopenaeus vannamei (Crustacea, Penaeidae) male sexual maturation and spermatozoal capacitation
}

Jorge Alfaro-Montoya, André Braga, Maribelle Vargas \& Rodolfo UmañaCastro

To cite this article: Jorge Alfaro-Montoya, André Braga, Maribelle Vargas \& Rodolfo UmañaCastro (2016): Ultrastructural demonstration of the model of Litopenaeus vannamei (Crustacea, Penaeidae) male sexual maturation and spermatozoal capacitation, Invertebrate Reproduction \& Development, DOI: 10.1080/07924259.2016.1244573

To link to this article: http://dx.doi.org/10.1080/07924259.2016.1244573

Published online: 13 Oct 2016.

Submit your article to this journal ¿

Џ Article views: 14

View related articles

View Crossmark data $\asymp$ 


\title{
Ultrastructural demonstration of the model of Litopenaeus vannamei (Crustacea, Penaeidae) male sexual maturation and spermatozoal capacitation
}

\author{
Jorge Alfaro-Montoya ${ }^{a}$, André Bragab (D), Maribelle Vargas ${ }^{c}$ (D) and Rodolfo Umaña-Castrod (D)

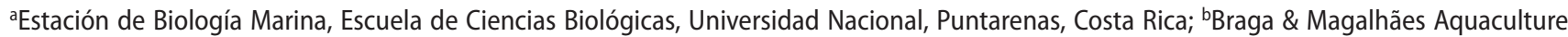 \\ Solutions, Belém, Brazil; ' Unidad de Microscopia Electrónica, Universidad de Costa Rica, San Pedro de Montes de Oca, Costa Rica; 'Laboratorio de \\ Análisis Genómico, Escuela de Ciencias Biológicas, Universidad Nacional, Heredia, Costa Rica
}

\begin{abstract}
The present study demonstrates ultrastructurally the model of Litopenaeus vannamei male sexual maturation and spermatozoal capacitation. The results show that phase 1 of the model occurred in the seminiferous tubules and includes spermatogenesis. In this phase, throughout differentiation of spermatogonia into late spermatids the following processes were observed: (1) decondensation of chromatin; (2) rupture of the nuclear envelope; (3) reduction of the cytoplasm and degeneration of organelles; (4) formation of the acrosome via fusion of cytoplasmic vesicles. Phase 2 comprised of spermatozoal maturation, a process that started with the transfer of late spermatids into the seminiferous ducts and ended with the formation of the acrosomal spike in the terminal ampoules. During this phase, development of the subacrosomal region and lateral electron-dense particles occurred in the seminiferous ducts, which is a novel finding of this species. Phase 3 was observed after spermatophore placement on the female thelycum and was mainly characterized by ultrastructural changes in the nucleus and the subacrosomal region. These results are in agreement with the model of male sexual maturation and spermatozoal capacitation proposed for $L$. vannamei.
\end{abstract}

\section{ARTICLE HISTORY}

Received 25 June 2016

Accepted 27 September 2016

\section{KEYWORDS}

Capacitation; Crustacea;

reproductive organs; spermatogenesis; spermatozoal maturation

\section{Introduction}

Morphological studies on Litopenaeus vannamei (Boone, 1931), the most important aquaculture shrimp species worldwide, have been reported frequently to improve knowledge of its biology and develop techniques that could enhance its performance in captivity (Oliveira Cesar et al. 2006; Suita et al. 2015). Studies focused on morphology of reproductive structures and processes have been also published (Diamond et al. 2008; CeballosVázquez et al. 2010; Alfaro-Montoya \& Hernández 2012). From these studies L. vannamei was shown to have a unistellate spermatozoon, which has a main body and a spike extending from the acrosome (Alfaro et al. 2007; Braga et al. 2013).

Alfaro-Montoya (2010) proposed a model to explain male sexual maturation and spermatozoal capacitation in Litopenaeus, in which ionic, biochemical and morphological changes undergone by spermatozoa after a period of spermatophore placement on the female thelycum, equip the cells with fertilization capacity (Braga et al. 2013). The model includes three phases: (1) spermatogenesis in the testes, where spermatogonia are differentiated into spermatids via meiotic divisions; (2) spermatozoal maturation, which starts when the late spermatids are transferred to the vas deferens and ends with formation of the acrosomal spike; (3) spermatozoal capacitation after spermatophore placement (Alfaro-Montoya 2010).

Some of the reproductive processes of the model have been used to develop techniques in aquaculture. For example, there are efforts to improve economic gains in shrimp farming via controlling sexual differentiation owing to higher growth rates in female penaeids (Pérez-Rostro \& Ibarra 2003; Moss \& Moss 2006). As part of this effort, Alfaro-Montoya et al. (2016) evaluated androgenic gland ablation as an alternative technology for monosex female culture. No sex reversal was observed, but it was concluded that spermatozoal maturation was stopped based on the phases of the model because only early spermatids were observed in seminiferous tubules and ducts of andrectomized males.

The mechanisms of spermatozoal capacitation are poorly understood, preventing in vitro reproduction of shrimp in laboratories. Some authors have demonstrated low in vitro fertilization rates using spermatophores collected from the terminal ampoules (Bray \& Lawrence 1992; Alfaro et al. 1993). The main reason for 
low in vitro fertilization rates is that mature spermatozoa are not equipped with fertilization capacity if the spermatophore was not previously attached to the thelycum (Wikramanayake et al. 1992; Alfaro et al. 2003, 2007). Therefore, understanding the mechanisms of capacitation could be useful to the development of biotechnologies that would allow spermatozoal induction without spermatophore placement on the thelycum (Braga et al. 2014).

Despite the relevance of the reproductive processes involved in the model for aquaculture research, the ultrastructure of the model for L. vannamei has not been demonstrated. These processes have been only reported fragmentarily. Xu et al. (2010) described the ultrastructure of spermatogenesis and histological observations were briefly reported by Muhammad and Shafi (2013) and Alfaro-Montoya (2013). The ultrastructure of spermatozoal capacitation has been reported separately (Alfaro et al. 2007; Aungsuchawan et al. 2011). Therefore, this study aimed to demonstrate ultrastructurally the model of $L$. vannamei male sexual maturation and spermatozoal capacitation.

\section{Material and methods}

\section{Animals}

L. vannamei juveniles were haphazardly selected from commercial semi-intensive culture in earthen ponds from Golfo de Nicoya, Costa Rica, and transferred to Estación de Biología Marina (EBM), Universidad Nacional, for further growth. Adult males and females were then transferred to the maturation laboratory of EBM under conventional controlled conditions for reproduction as described previously (Alfaro-Montoya 2013).

\section{Tissue sampling}

For transmission electron microscopy, male sexual organs were dissected under cold anesthetization from six cultured young specimens of $L$. vannamei (body weight (b.w.) = 9-12 g). Additionally, spermatophores from two adult males (b.w. = $30 \mathrm{~g}$ ) were collected by manual ejaculation and two inseminated $L$. vannamei females (b.w. = $37 \mathrm{~g}$ ) from maturation tanks were isolated in spawning tanks for 4-5 $\mathrm{h}$ before removing the attached sperm mass.

Regions of sexual organs and compact spermatophores were fixed whole. Sperm masses were expelled from spermatophores collected from female thelyca before fixation. Tissues were fixed with a solution of paraformaldehyde (2.0\%), glutaraldehyde (2.5\%), and sucrose $(5.0 \%)$ in $0.1 \mathrm{M}$ sodium cacodylate buffer at $\mathrm{pH} 7.4$, according to Ro et al. (1990). The samples were transferred to the Centro de Investigación en Estructuras Microscópicas (CIEMIC), University of Costa Rica, where microscopy was conducted separately for each collected region of the male reproductive system and sperm mass.

\section{Tissue ultrastructure}

While in fixative, samples were observed under light microscopy to identify sperm masses and eliminate unnecessary material. After three washes in fresh $0.1 \mathrm{M}$ cacodylate buffer, samples were postfixed in 1\% OsO4 in $0.1 \mathrm{M}$ cacodylate buffer, $\mathrm{pH} 7.4$, at room temperature for $2 \mathrm{~h}$. Samples were then rinsed with $0.1 \mathrm{M}$ cacodylate buffer and distilled water several times, dehydrated in an ascending series of ethanol, then embedded, via propylene oxide, in Spurr's resin. Ultrathin sections (40-60 nm thickness) were cut with an ultramicrotome using a diamond knife, picked up on copper grids, stained sequentially with uranyl acetate and lead citrate, and examined under a transmission electron microscope (Hitachi H-7700) at $100 \mathrm{kV}$. As a reference, histological sections of testes stained with hematoxylin and eosin were also processed as described previously (Alfaro-Montoya et al. 2016).

\section{Results}

\section{Phase 1: spermatogenesis in testes}

Testicular lobules are composed of convoluted seminiferous tubules where different stages of spermatogenesis are present at the same time (Figure 1). When seen in crosssection, each seminiferous tubule has three regions: a germinal region with spermatogonia located at the periphery of the tubules, a large and central spermatogenic center with spermatocytes and spermatids, and a layer of elongate nurse cells, surrounding the spermatogenic center (Figure 1(A)). The phases of spermatogenesis are mostly synchronized in the spermatogenic center within seminiferous tubules, but different phases are developing in adjacent tubules (Figure 1(B)). The external layer of seminiferous tubules is formed by connective tissue (Figure 1(C)). Seminiferous ducts for collecting immature spermatozoa can be seen within seminiferous tubules.

The spermatogonium is a large oval-shaped cell with a large nucleus (mean \pm S.D. nuclear diameter, n.d., $=7.4 \pm 0.3 \mu \mathrm{m}$ ), containing a nucleolus. The cytoplasm has mitochondria and small electron-dense bodies at the periphery of the nuclear surface (Figure 1(C)).

Primary spermatocytes are spherical cells with a nucleus mostly composed of uncondensed chromatin (Figure 1(D)-(F)). The nucleus is similar in size (n.d. $=7.9 \pm 1.3 \mu \mathrm{m}$ ) to those of spermatogonia. Mitochondria and ribosomes are abundant in the cytoplasm, which has its volume mainly occupied by rough endoplasmic reticulum, proliferating parallel to the nuclear envelope (Figure 1(D) and (F)). A 

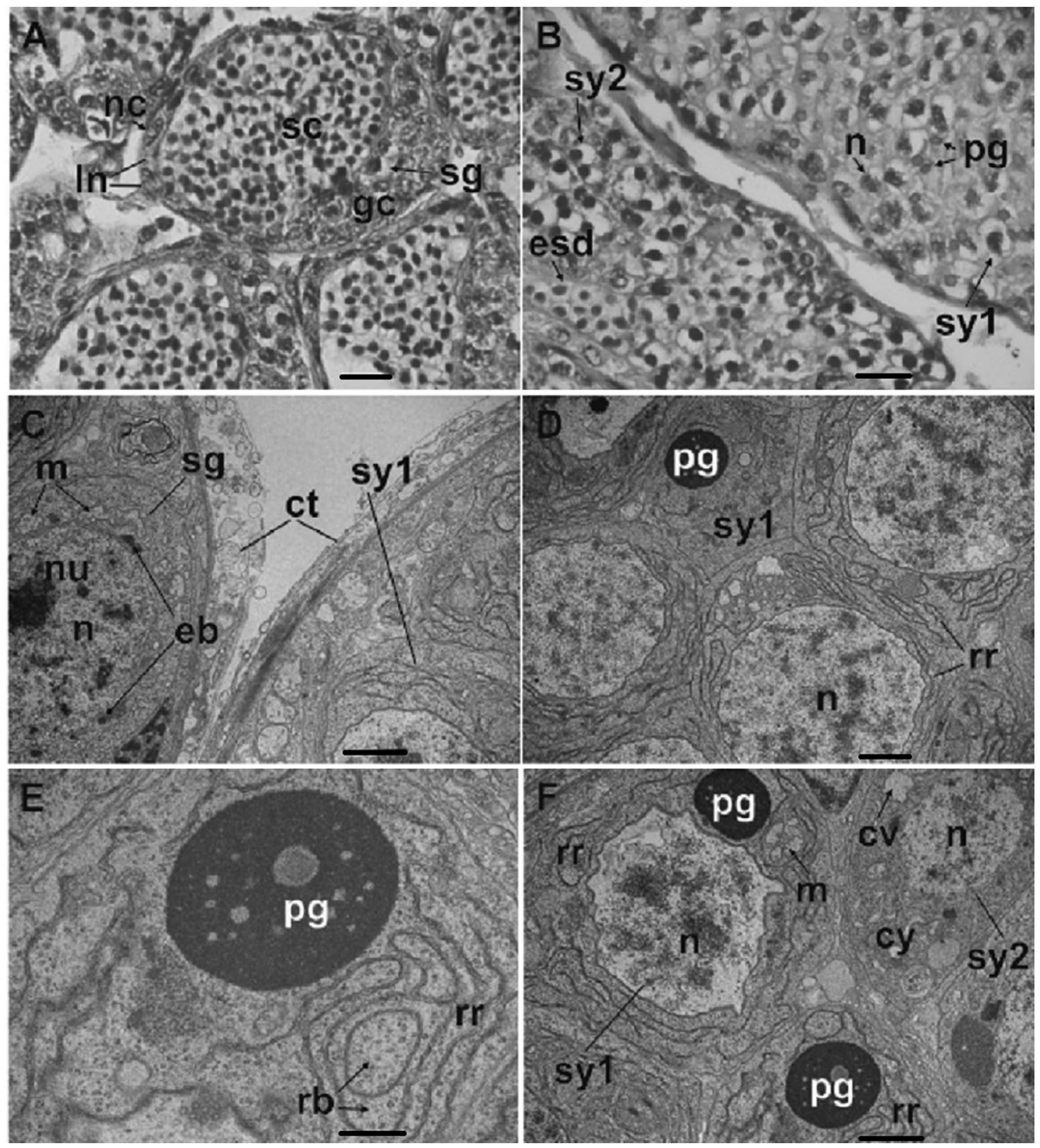

Figure 1. Light microscopy of Litopenaeus vannamei seminiferous tubules (A, B) and ultrastructure of spermatogonia (C), primary (D-F) and secondary spermatocytes (F) contained in testes.

Notes: ct: connective tissue; cy: cytoplasm; cv: cytoplasmic vesicles; esd: early spermatid; eb: electron-dense bodies; pg: electron-dense vesicle; gc: germinal region; In: layer of nurse cells; m: mitochondria; nu: nucleoli; n: nucleus; nc: nurse cell; sy1: primary spermatocyte; rb: ribosomes; rr: rough endoplasmic reticulum; sy2: secondary spermatocyte; sc: spermatogenic region; sg: spermatogonia. Scale bars = A, B: $20 \mu \mathrm{m} ; \mathrm{C}, \mathrm{D}, \mathrm{F}: 2 \mu \mathrm{m} ; \mathrm{E:}: 800 \mathrm{~nm}$.

membrane-bound electron-dense vesicle of eosinophilic nature under light microscopy is embedded in the endoplasmic reticulum vesicles and located near to the nuclear region (Figure 1(B), (D)-(F)). Secondary spermatocytes develop after the first meiotic division, generating a smaller nucleus composed of highly condensed chromatin and limited by the envelope (Figure 1(F); n.d. $=3.4 \pm 0.2 \mu \mathrm{m}$ ). The volume of the cytoplasmic region, the amount of rough endoplasmic reticulum, and number of mitochondria are reduced, resulting in the presence of vesicles, and the electron-dense vesicle is absent in secondary spermatocytes (Figure 1(F)). 

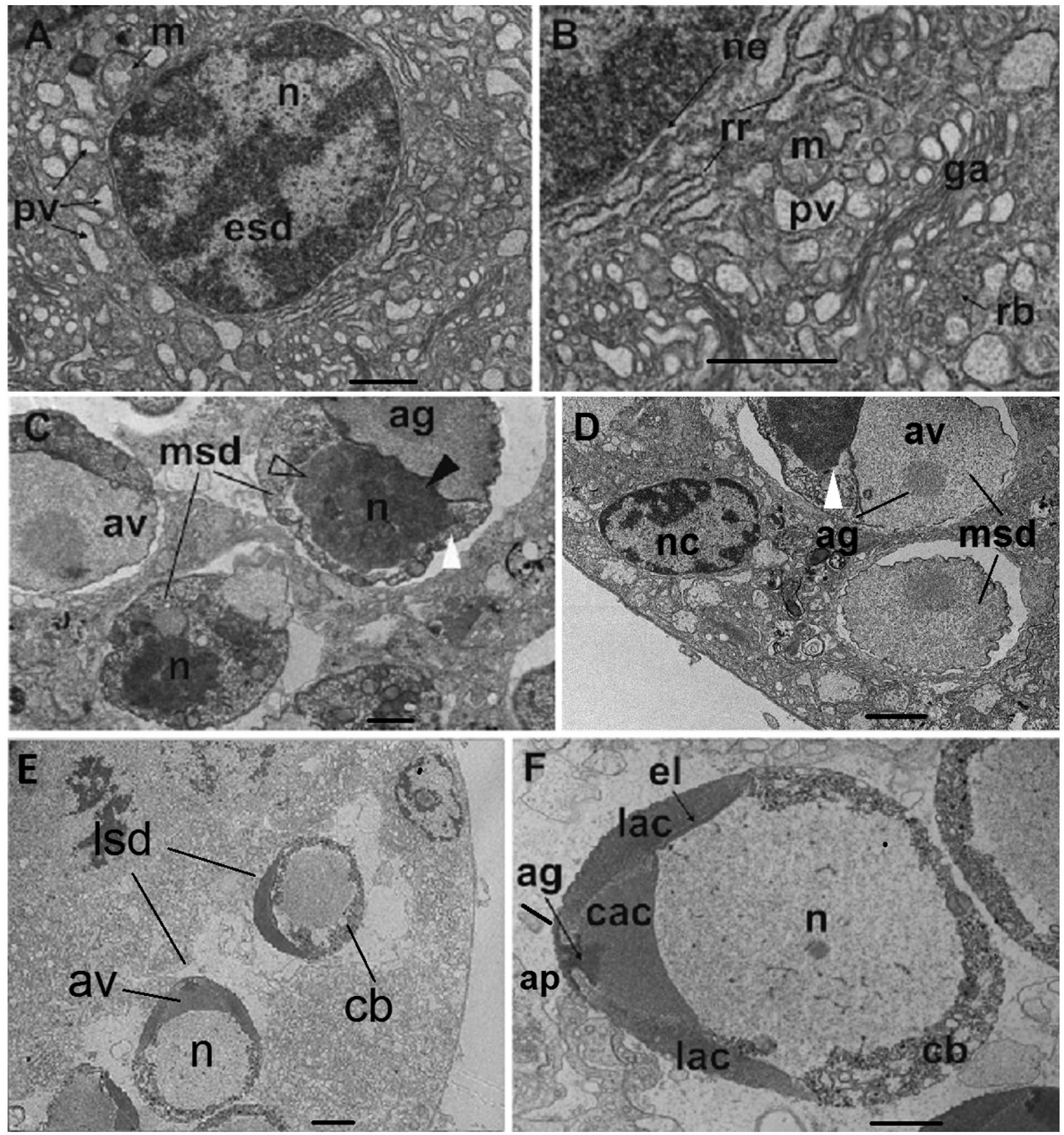

Figure 2. Fine structure of early (A, B), mid- (C, D) and late spermatids $(E, F)$ in L. vannamei testes.

Notes: av: acrosomal vesicle; ag: anterior granule; ap: apical protuberance; cac: central acrosomal cap; cb: cytoplasmic band; esd: early spermatid; el: electrondense inner layer; ga: Golgi-like body; Isd: late spermatid; lac: lateral acrosomal cap; msd: mid-spermatid; m: mitochondria; ne: nuclear envelope; n: nucleus; nc: nurse cell; pv: proacrosomal vesicle; rb: ribosomes; rr: rough endoplasmic reticulum; black arrowhead: electron-denser nuclear region; unfilled arrowhead: electronically less-dense nuclear region; white arrowhead: rupture of the nuclear envelope. Scale bars = A-C, F: $1 \mu \mathrm{m} ; \mathrm{D}, \mathrm{E}: 2 \mu \mathrm{m}$.

Early spermatids have a spherical nucleus with condensed chromatin and some heterochromatin, producing a granular pattern (Figure 2(A), (B); n. d. $=4.3 \pm 0.0 \mu \mathrm{m}$ ). In the cytoplasmic region, strands of rough endoplasmic reticulum with abundant associated ribosomes parallel to the nuclear envelop are present and Golgi-like bodies and mitochondria are occasionally observed. Abundant electron-lucent proacrosomal vesicles are characteristic of early spermatids (Figure 2(A) and (B)).

In mid-spermatids, the nucleus is composed of condensed chromatin, although it is possible to observe that decondensation has begun, which results in two lateral regions distinguished by differences in electron density (Figure 2(C)). At this stage, the breakdown of the nuclear 
envelope occurs and the nuclear content is mixed with the cytoplasm in some areas (Figure 2(C) and (D)). The cytoplasm is considerably reduced and Golgi-like bodies, rough endoplasmic reticulum, and mitochondria are present, although numerically reduced. The cytoplasmic region surrounds the posterior region of the nucleus and is anteriorly limited by an acrosomal vesicle, which was formed via fusion of the proacrosomal vesicles. An anterior granule is observed within the acrosomal vesicle, which is ultrastructurally a spherical and more electron-dense region (Figure 2(C) and (D)).

The most advanced stage of spermiogenesis in testes was observed in late spermatids, which have a nucleus composed of decondensed chromatin with a flocculent appearance and surrounded posterolaterally by a thin cytoplasmic band. The perinuclear cytoplasm has a granular pattern and is composed of some mitochondria and abundant vesicles. The acrosomal vesicle has undergone significant changes, assuming a slight internal concave shape with an apical protuberance. Also, the acrosomal vesicle includes the acrosomal cap and the anterior granule at this stage. The acrosomal cap is composed of two regions: two lateral acrosomal caps and a central cap. The lateral caps have heterogeneous material with electron-dense granules and have a clear electron-dense inner layer at the border with the nucleus. The central cap is composed of more homogeneous material. The anterior granule is more electron-dense in comparison with mid-spermatids and has migrated to the apical region of late spermatids (Figure 2(E) and (F)).

\section{Phase 2: spermatozoal maturation in the vas deferens}

Late spermatids are transferred to seminiferous ducts, where spermatozoal maturation begins. Figure 3 shows transitional stages between late spermatids and early immature spermatozoa in the seminiferous ducts. These cells have a similar ultrastructure to the late spermatids within testicular lobules, but some new structures have begun to develop. These include a subacrosomal region and lateral electron-dense particles of the anterior granule, which is accompanied by anterior granule expansion into the central acrosomal cap (Figure 3).

The maturation of spermatozoa continues in the vas deferens and ends only at the level of terminal ampoules, where spermatophores contain mature spermatozoa. The cells observed in the spermatophore are composed of a spherical main body and a single appendage extending from the acrosome, the spike (Figure 4(A)). Spermatozoa have chromatin in a decondensed state, but with a fibrous pattern made up of a granular network and filaments (Figure 4(B)). The perinuclear cytoplasmic band has not undergone significant changes. The internal concavity of the acrosomal vesicle is more evident and the vesicle is composed of a subacrosomal region, acrosomal cap, and spike (Figure $4(\mathrm{~A})$ ). The subacrosomal region has extended and includes two regions: a filamentous meshwork and a clear zone (Figure 4(B)). The lateral acrosomal caps keep the inner electron-dense layer, whereas the central cap is more electron-dense (Figure 4(B)). The anterior granule is no longer visible and has turned into the spike, keeping the lateral electron-dense particles at the base of the spike (Figure 4(A) and (B)).

\section{Phase 3: spermatozoal capacitation after spermatophore attachment to the thelycum}

Spermatozoa removed from female thelyca after attachment have the same ultrastructure as spermatozoa removed from the spermatophore, including a main body composed of a nucleus posterolaterally surrounded by the cytoplasmic band and an acrosomal vesicle expanded anteriorly into a spike (Figure $4(C)$ ). However, some ultrastructural developments were observed 3-4 $\mathrm{h}$ after spermatophore attachment, especially in the nucleus and the acrosomal vesicle. In the nucleus, the chromatin is decondensed, but the granular network and filaments are less abundant, resulting in a more electron-translucent pattern (Figure 4(D)). In the acrosomal vesicle, the internal concavity is decreased. The degree of electron density is increased in the acrosomal cap and spike. The filamentous meshwork has proliferated to cover most of the subacrosomal region (Figure 4(C) and (D)).

\section{Discussion}

The seminiferous tubules of $L$. vannamei contained only spermatogonia, spermatocytes and spermatids. Spermatozoal maturation began in the seminiferous ducts and ended in the terminal ampoules with the formation of the acrosomal spike. After spermatophore attachment to the thelycum, mature spermatozoa had undergone ultrastructural changes. Therefore, the results reported in this study are in agreement with the model proposed by Alfaro-Montoya (2010).

The model of male sexual maturation and spermatozoal capacitation in L. vannamei is in disagreement with previous observations for Fenneropenaeus chinensis, Metapenaeus monoceros, and Parapenaeus longirostris (Medina 1994; Abraham et al. 2007; Kang et al. 2008). Spermatozoa with an acrosomal spike were observed in the seminiferous tubules of these species. By contrast, the most advanced stage of germ cells in the testes of Litopenaeus setiferus, Litopenaeus stylirostris, Litopenaeus schmitti, and Sicyonia ingentis was the late spermatid, 

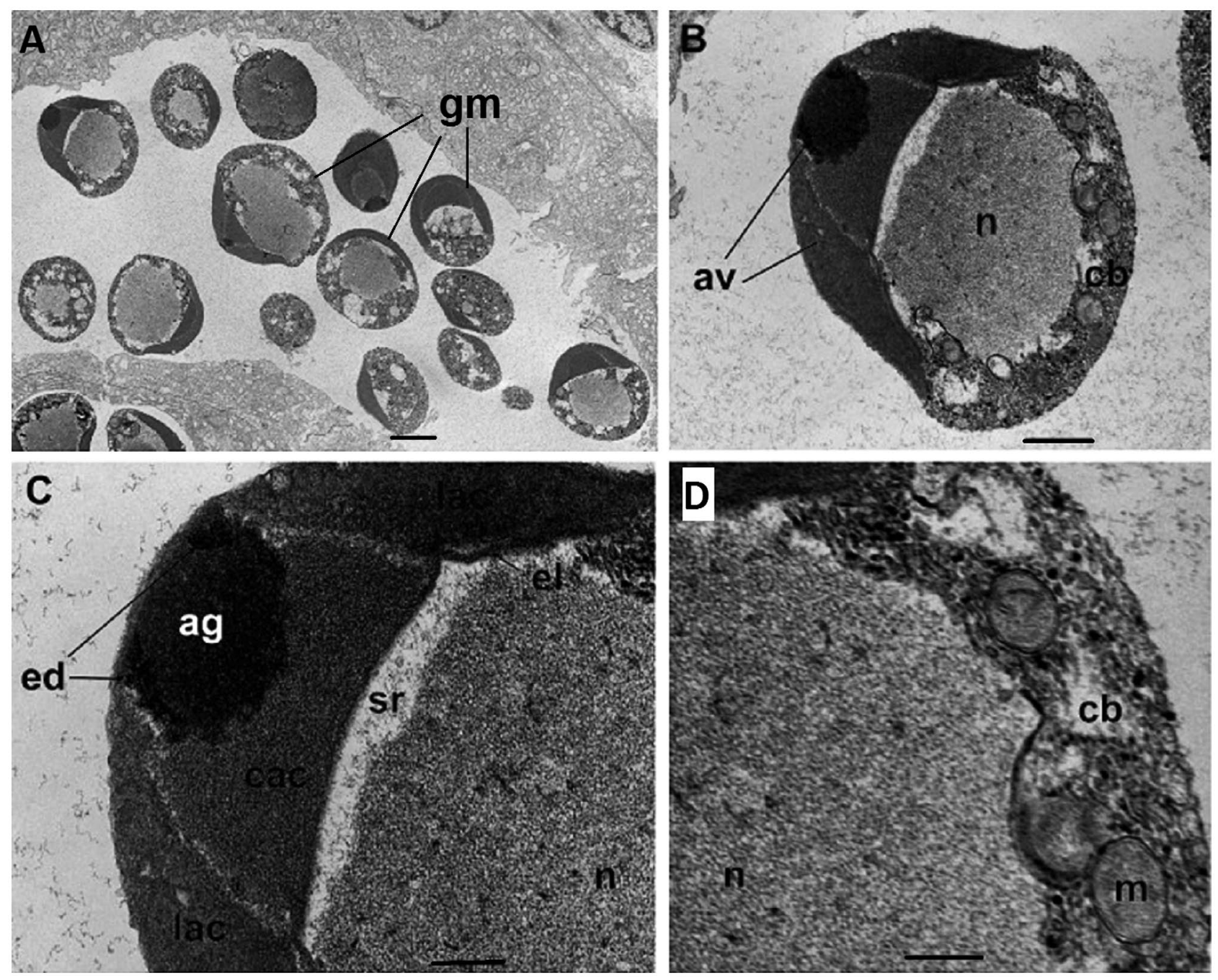

Figure 3. Ultrastructure of spermatozoal maturation in Litopenaeus vannamei seminiferous ducts.

Notes: av: acrosomal vesicle; ag: anterior granule; cac: central acrosomal cap; cb: cytoplasmic band; ed: electron-dense particles of the anterior granule; el: electrondense inner layer; gm: germ cells at transitional stages between late spermatids and early immature spermatozoa; lac: lateral acrosomal cap; $\mathrm{m}$ : mitochondria; $\mathrm{n}$ : nucleus; sr: subacrosomal region. Scale bars $=A: 2 \mu \mathrm{m} ; \mathrm{B}: 1 \mu \mathrm{m} ; \mathrm{C}, \mathrm{D}: 400 \mathrm{~nm}$.

which continue their maturation in the vas deferens (King 1948; Shigekawa \& Clark Jr. 1986; Alfaro 1994; Fransozo et al. 2016). Thus, the model that consists of spermatogenesis in the testes, spermatozoal maturation in the vas deferens, and spermatozoal capacitation after spermatophore attachment is most likely an apomorphic feature for the genus Litopenaeus, shared homoplasically with sicyoniids. However, further descriptions for species of Dendrobranchiata are required to test this hypothesis.

Alfaro-Montoya (2013) and Muhammad and Shafi (2013) reported histological descriptions of the morphological organization of the germ cells within the seminiferous tubules of Litopenaeus, where phase 1 occurs. Our study has revealed that the cells are organized into three different regions: a germinal region located at the periphery of the tubules and composed of spermatogonia, a central spermatogenic center composed of spermatocytes and spermatids, and a layer of elongate nurse cells. This zonation of the germ cells within L. vannamei seminiferous tubules was not previously reported.

The zonation of germ cells within seminiferous tubules of shrimp-like decapods has been described in the literature. The presence of spermatogonia within a peripheral germinal region and more advanced cellular phases within a spermatogenic region has been observed for other penaeids (Chow et al. 1991; Medina 1994). Likewise, nurse cells have been observed in crustacean seminiferous tubules, providing nourishment and some hormones during spermatogenesis (Hinsch 1969). However, the positioning of the nurse cells in the seminiferous tubules is not related to phylogeny of shrimp-like decapods. The presence of nurse cells in a layer at the tubule edge, as observed in the present study, is congruent with the pattern described by Arsenault et al. (1979) for Crangon 

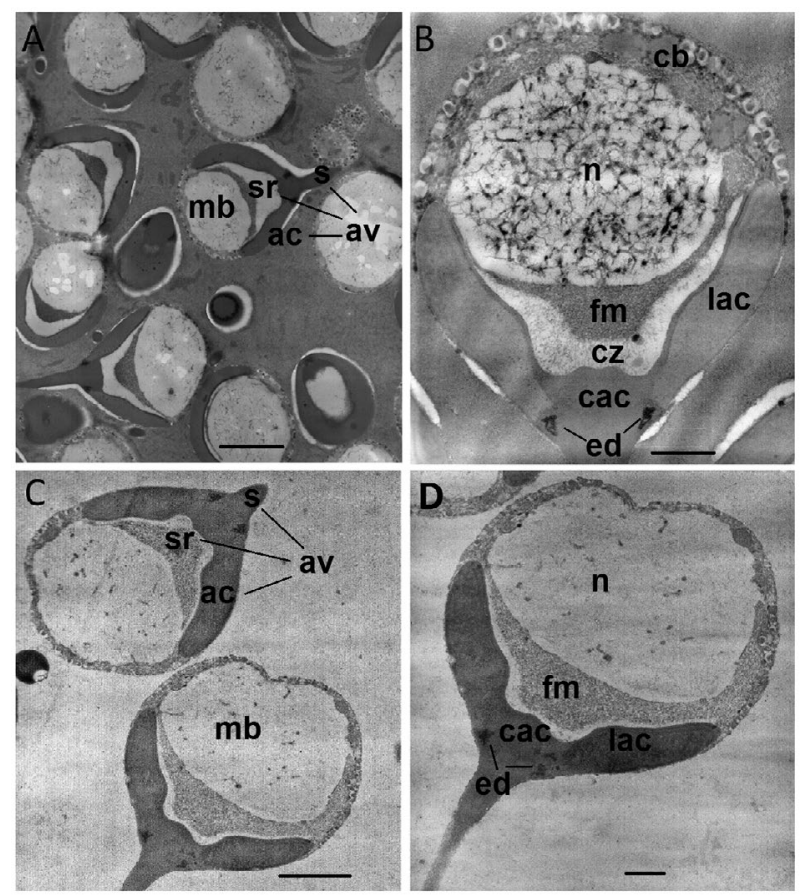

Figure 4. Litopenaeus vannamei mature (A, B) and capacitated spermatozoa (C, D).

Notes: ac: acrosomal cap; av: acrosomal vesicle; cac: central acrosomal cap; cz: clear zone; cb: cytoplasmic band; ed: electron-dense particles; fm: filamentous meshwork; lac: lateral acrosomal cap; mb: main body; n: nucleus; s: spike; sr: subacrosomal region. Scale bars $=A: 2 \mu \mathrm{m} ; B, C: 1 \mu \mathrm{m} ; \mathrm{D}: 500 \mathrm{~nm}$.

septemspinosa. However, nurse cells were observed associated with spermatogonia in the germinal region of the caridean Macrobrachuim rosenbergii, and the penaeids Penaeus indicus and M. monoceros (Mohamed \& Diwan 1993; Abraham et al. 2007; Poljaroen et al. 2010). Thus, further comparative studies are required to improve knowledge of the role of the positioning of nurse cells within seminiferous tubules.

Differentiation of spermatogonia into late spermatids via meiotic divisions was observed inside seminiferous tubules. This can be summarized into the following processes: (1) decondensation of chromatin, which was preceded by condensation from spermatogonia to secondary spermatocytes and, then, gradual decondensation in the more advanced stages of germ cells; (2) rupture of the nuclear envelope in mid-spermatids, which resulted in mixing of nucleoplasm and cytoplasmic contents; (3) reduction of the cytoplasm and degeneration of organelles, which results in an abundant population of vesicles in early spermatids; (4) formation of the acrosome, beginning with fusion of the cytoplasmic vesicles. The proacrosomal vesicle is observed in mid-spermatids and undergoes significant changes in late spermatids. The ultrastructure of phase 1 of the model observed in this study is congruent with the previous report on L. vannamei spermatogenesis (Xu et al. 2010).
The ultrastructure of the phase 2 was characterized by development of new structures, such as the subacrosomal region and lateral electron-dense particles of the anterior granule, after transfer of the late spermatids to the seminiferous ducts. The presence of these structures has been reported only in L. vannamei mature spermatozoa present in spermatophores collected from the terminal ampoule (Xu et al. 2010; Alfaro-Montoya 2013). Thus, the conclusion that the development of the subacrosomal region and lateral electron-dense particles occurs in the seminiferous ducts is a novel finding reported for this species. These electron-dense particles have been also observed in L. schmitti spermatozoa from the median vas deferens (Fransozo et al. 2016). Most of the studies on the ultrastructure of shrimp spermatogenesis available in the literature are restricted to observations from seminiferous tubules and spermatophores and, therefore, more attention to the full male reproductive system is required to determine the ultrastructural changes from seminiferous ducts to terminal ampoule.

At the end of phase 2, spermatozoal maturation is completed and the cells consist of the following sections: a spherical main body composed of a nucleus with a fibrous pattern made up of a granular network and filaments posterolaterally surrounded by a cytoplasmic band; and the spike extending from the acrosome, which also includes the acrosomal cap and the subacrosomal region divided into a filamentous meshwork and a clear zone. In phase 3, the mature spermatozoa undergo changes mainly related to the nucleus (granular network and filaments are less abundant) and subacrosomal region (enlargement of the filamentous meshwork). The ultrastructure of both mature and capacitated spermatozoa is in agreement with previous reports for L. vannamei (Alfaro et al. 2007; Aungsuchawan et al. 2011). However, it has also been indicated that spike elongation occurs after transfer to female thelyca (Xu et al. 2010).

The ultrastructural changes undergone by distinct germ cells throughout the phases of $L$. vannamei male sexual maturation and spermatozoal capacitation are most likely related to fertilization. Although the ultrastructure of L. vannamei fertilization is unknown, it is widely accepted that this process in dendrobranchiates begins with a visible acrosomal reaction, consisting of biochemical, ionic and morphological changes in the acrosomal complex necessary for spermatozoal incorporation into the egg (Kruevaisayawan et al. 2008; Braga et al. 2013). The penaeid acrosomal reaction is initiated with spike depolymerization via acrosomal vesicle rupture and ends with exocytosis of the cell contents (Braga et al. 2013). The reduction of the cytoplasm and the degeneration of the organelles suggest decreasing metabolism throughout spermatogenesis (Kang et al. 2008). However, as demonstrated in our study, 
changes undergone by the cytoplasm are also involved in differentiation of the acrosomal vesicle, which plays a role in egg recognition and attachment via the spike tip (Braga et al. 2013). The development of the subacrosomal region (phase 2) and the subsequent enlargement of the filamentous meshwork (phase 3) are most likely related to exocytosis because it becomes progressively denser and larger throughout the acrosomal reaction, forcing the rupture of the acrosomal vesicle (Alfaro et al. 2003, 2007). Finally, the pattern of chromatin decondensation and absence of the nuclear envelope have been suggested as factors that facilitate exocytosis at the end of the acrosomal reaction (Shigekawa \& Clark 1986).

Complementary biochemical evidence (phosphorylation activity) to further support the ultrastructural changes associated with the capacitation of L. vannamei spermatozoa were given by Aungsuchawan et al. (2011). Also in L. occidentalis, supporting evidence by inducing the acrosome reaction in vitro was provided by Alfaro et al. (2007). Additional evidence of capacitation from other Litopenaeus species (Fransozo et al. 2016) will contribute to an understanding and control of this limiting in vitro fertilization factor.

The present study demonstrated ultrastructurally the model of $L$. vannamei male sexual maturation and spermatozoal capacitation. The model is composed of three phases: (1) spermatogenesis in testes, a process that comprises differentiation of spermatogonia to late spermatids in seminiferous tubules and is characterized by decondensation of the chromatin, rupture of the nuclear envelope, reduction of cytoplasm via degeneration of organelles, and development of the acrosomal vesicle; (2) spermatozoal maturation, which begins when late spermatids are transferred to seminiferous ducts, where the subacrosomal region is developed, and ends only with the formation of the acrosomal spike in the terminal ampoules; (3) spermatozoal capacitation, in which mature spermatozoa undergo significant ultrastructural change mainly related to the nucleus and subacrosomal region after spermatophore attachment to the female thelycum.

\section{Acknowledgments}

This research is part of the project: Sex reversal of the cultured marine shrimp, L. vannamei, in cooperation with Prof. Amir Sagi, Life Sciences Department, Ben-Gurion University of the Negev. We thank unknown referees for their valuable comments.

\section{Disclosure statement}

No potential conflict of interest was reported by the authors.

\section{Funding}

This work was supported by Consejo Nacional de Rectores (CONARE), Costa Rica.

\section{ORCiD}

André Braga (iD http://orcid.org/0000-0001-7579-4472

Maribelle Vargas (iD http://orcid.org/0000-0002-4935-4243

Rodolfo Umaña-Castro (iD http://orcid.org/0000-0003-00412788

\section{References}

Abraham J, Manisseri MK, Sanil NK. 2007. Spermatogenesis and spermatozoal ultrastructure in Metapenaeus monoceros (Fabricius, 1798). Indian Journal of Fisheries. 54:1-9.

Alfaro J. 1994. Ultraestructura de la glándula androgénica, espermatogénesis y oogénesis de camarones marinos (Decapoda: Penaeidae) [Ultrastructure of the androgenic gland, spermatogenesis and oogenesis of marine shrimps]. Revista de Biología Tropical. 42:121-129.

Alfaro J, Lawrence AL, Lewis D. 1993. Interaction of bacteria and male reproductive system blackening disease of captive Penaeus setiferus. Aquaculture. 117:1-8.

Alfaro J, Muñoz N, Vargas M, Komen J. 2003. Induction of sperm activation in open and closed thelycum penaeoid shrimps. Aquaculture. 216:371-381.

Alfaro J, Ulate K, Vargas M. 2007. Sperm maturation and capacitation in the open thelycum shrimp Litopenaeus (Crustacea: Decapoda: Penaeoidea). Aquaculture. 270:436442.

Alfaro-Montoya J. 2010. The reproductive conditions of male shrimps' genus Penaeus, sub-genus Litopenaeus (open thelyca penaeoid shrimps): a review. Aquaculture. 300:1-9.

Alfaro-Montoya J. 2013. Descripción histológica de la oogénesis y espermatogénesis del camarón de cultivo, Litopenaeus vannamei [Histological description of oogenesis and spermatogenesis of the cultured shrimp, Litopenaeus vannamei]. Revista de Biología Marina y Oceanografía. 48:335-344.

Alfaro-Montoya J, Hernández L. 2012. The histological structure of the androgenic gland and cellular cord of the male reproductive system of adult Litopenaeus and Rimapenaeus byrdi. Journal of Crustacean Biology. 32:351-357.

Alfaro-Montoya J, Hernández-Noguera L, Vega-Alpízar L, Umaña-Castro R. 2016. Effects of androgenic gland ablation on growth, sexual characters and spermatogenesis of the white shrimp, Litopenaeus vannamei (Decapoda: Penaeidae) males. Aquaculture Research. 47:2768-2777.

Arsenault AL, Clattenburg RE, Odense PH. 1979. Spermiogenesis in the shrimp, Crangon septemspinosa, Say. Canadian Journal of Zoology. 57:486-498.

Aungsuchawan S, Browdy CL, Withyachumnarnkul B. 2011. Sperm capacitation of the shrimp Litopenaeus vannamei. Aquaculture Research. 42:188-195.

Braga A, Nakayama CL, Poersch L, Wasielesky W. 2013. Unistellate spermatozoa of decapods: comparative evaluation and evolution of the morphology. Zoomorphology. 132:261-284. 
Braga A, Suita de Castro LA, Poersch LH, Wasielesky W. 2014. Spermatozoal capacitation of pink shrimp Farfantepenaeus paulensis. Aquaculture. 430:207-210.

Bray WA, Lawrence AL. 1992. Reproduction of Penaeus species in captivity. In: Fast A \& Lester LJ, editors. Marine shrimp culture: principles and practices. The Netherlands: Elsevier Science Publisher B.V.; p. 93-169.

Ceballos-Vázquez BP, Palacios E, Aguilar-Villavicencio J, Racotta IS. 2010. Gonadal development in male and female domesticated whiteleg shrimp, Litopenaeus vannamei, in relation to age and weight. Aquaculture. 308:116-123.

Chow S, Dougherty MM, Dougherty WJ, Sandifer PA. 1991. Spermatophore formation in the white shrimps Penaeus setiferus and $P$. vannamei. Journal of Crustacean Biology. 11:201-216.

Diamond S, Powell A, Shields RJ, Rowley AF. 2008. Is spermatophore melanisation in captive shrimp (Litopenaeus vannamei) a result of an auto-immune response? Aquaculture. 285:14-18.

Fransozo V, Fernandes AB, López-Greco LS, Zara FJ, Santos DC. 2016. Functional morphology of the male reproductive system of the white shrimp Litopenaeus schmitti (Burkenroad, 1936) (Crustacea, Penaeidea) compared to other Litopenaeus. Invertebrate Reproduction \& Development. 60:161-174. doi: 10.1080/07924259.2016.1174158

Hinsch GW. 1969. Microtubules in the sperm of the spider crab, Libinia emarginata L. Journal of Ultrastructure Research. 29:525-534.

Kang X, Ge S, Guo M, Liu G, Mu S. 2008. A transmission electron microscopy investigation: the membrane complex in spermatogenesis of Fenneropenaeus chinesis. Cytotechnology. 56:113-121.

King JE. 1948. A study of the reproductive organs of the common marine shrimp Penaeus setiferus. Biological Bulletin. 94:244-262.

Kruevaisayawan $H$, Vanichviriyakit $R$, Weerachatyanukul W, lamsaard S, Withyachumnarnkul B, Basak A, Tanphaichitr $\mathrm{N}$, Sobhon P. 2008. Induction of the acrosome reaction in blacktiger shrimp (Penaeus monodon) requires sperm trypsinlike enzyme activity. Biology of Reproduction. 79:134-141.

Medina A. 1994. Spermiogenesis and sperm structure in the shrimp Parapenaeus longirostris (Crustacea: Dendrobranchiata): comparative aspects among decapods. Marine Biology. 119:449-460.
Mohamed KS, Diwan AD. 1993. Spermatogenesis and spermatophore formation in the Indian white prawn Penaeus indicus H. Milne Edwards. Journal of the Marine Biological Association of India. 35:180-192.

Moss DR, Moss SM. 2006. Effects of gender and size on feed acquisition in the pacific white shrimp Litopenaeus vannamei. Journal of the World Aquaculture Society. 37:161-167.

Muhammad F, Shafi M. 2013. Histological observations on development of sperms in Litopenaeus vannamei (Boone, 1931) (Crustacea: Decapoda). International Journal of Biology and Biotechnology. 10:597-599.

Oliveira Cesar JR, Zhao B, Malecha S, Ako H, Yang J. 2006. Morphological and biochemical changes in the muscle of the marine shrimp Litopenaeus vannamei during the molt cycle. Aquaculture. 261:688-694.

Pérez-Rostro Cl, Ibarra AM. 2003. Heritabilities and genetic correlations of size traits at harvest size in sexually dimorphic pacific white shrimp (Litopenaeus vannamei) grown in two environments. Aquaculture Research. 34:1079-1085.

Poljaroen J, Vanichviriyakit R, Tinikul Y, Phoungpetchara I, Linthong V, Weerachatyanukul W, Sobhon P. 2010. Spermatogenesis and distinctive mature sperm in the giant freshwater prawn, Macrobrachium rosenbergii (De Man, 1879). Zoologischer Anzeiger. 249:81-94.

Ro S, Talbot P, Leung-Trujillo J, Lawrence AL. 1990. Structure and function of the vas deferens in the shrimp Penaeus setiferus: segments 1-3. Journal of Crustacean Biology. 10:455-468.

Shigekawa K, Clark Jr. WH. 1986. Spermiogenesis in the marine shrimp, Sicyonia ingentis. Development, Growth and Differentiation. 28:95-112.

Suita SM, Cardozo AP, Romano LA, Abreu PC, Wasielesky W. 2015. Development of the hepatopancreas and quality analysis of post-larvae pacific white shrimp Litopenaeus vannamei produced in a BFT system. Aquaculture International. 23:449-463.

Wikramanayake AH, Uhlinger KR, Griffin FJ, Clark Jr. WH. 1992. Sperm of the shrimp Sicyonia ingentis undergo a bi-phasic capacitation accompanied by morphological changes. Development, Growth and Differentiation. 34:347-355.

Xu Y, Liu X, Zhang L, Hu C. 2010. Studies on the ultrastructure of spermatogenesis in shrimp, Litopenaeus vannamei. Journal of Tropical Oceanography. 29:89-93. 